\title{
Economic determinants of emerging stock market interdependence
}

\author{
Elna Pretorius \\ Department of Economics, University of Pretoria 0001, Pretoria, South Africa
}

\begin{abstract}
There is a wealth of literature on how integrated stock markets are, but very few studies attempts to determine why stock markets are integrated. However, it is arguably even more important to understand the driving forces behind stock market relationships than to know whether they exist. Such an understanding will provide a better grasp of the functioning of the global stock markets and allow investors and policy-makers to ask additional questions such as: Would an increase in bilateral trade between two countries, for example due to a new trade agreement, change the interdependence of their stock markets? If the growth rate of a particular emerging market falls due to the current global economic downturn, will its stock market drag along all the other stock markets or can it be known beforehand which stock markets are more likely to follow? This study empirically estimates cross-section and time-series models to determine the fundamental factors that influence the correlation and evolvement of the correlation between emerging stock markets.
\end{abstract}

Keywords: Emerging markets; International financial markets; Macroeconomics and financial markets

\section{Introduction}

The financial crisis that erupted in Asia in 1997 and 1998 led to sharp declines in stock markets, currencies and other asset prices. It also threatened these countries' financial systems and disrupted their real economies, with large contractions in activity, which created a human crisis alongside the

Corresponding author. Tel.: +27-1242-03461; fax: +27-1236-25207; email: emoolman@hakuna.up.ac.za 
financial one. In addition to its severe effects in Asia, the crisis put pressure on emerging markets outside the region, and has contributed to virulent contagion and volatility in international financial markets. The so-called 'contagion' effect of the crisis drew a lot of attention to the linkages among emerging stock markets and raised the fundamental question: What determines the extent of interdependence among emerging stock markets?

International investors need to understand the forces behind the interdependence of emerging stock markets in order to realize the potential risks and rewards of global diversification. Likewise, policy-makers need to understand the driving forces behind emerging stock market interdependence, since from their point of view, contagion means irrational capital flows, especially capital outflows when capital is needed the most. This reduces the benefits of financial liberalization. Can the extent of interdependence between the emerging markets be explained? Put differently, is the co-movement of emerging stock markets 'contagion' in the true sense of the word or can it be explained by fundamentals?

This calls for an examination of the factors that influence the relationships and dynamic linkages between emerging stock markets. Such an understanding will provide a better grasp of the functioning of the global stock markets, and allow investors and policy-makers to ask additional questions such as: is the level of interdependence among emerging stock markets remaining constant or is it increasing over time? What influence did the 1998 emerging market crisis have on the level of stock market interdependence: did it cause a permanent or temporary increase in stock market interdependence or did it have no lasting effect? Are regional stock markets more interdependent than stock markets in general? Would an increase in bilateral trade between two countries, for example, due to a new trade agreement, change the interdependence of their stock markets? If the growth rate of a particular emerging market falls due to the current global economic downturn, will its stock market drag along all the other stock markets or can it be known beforehand which stock markets are more likely to follow? In addition, if the influence of economic indicators can be estimated empirically, it will enable policy-makers and investors to analyze different scenarios, and to predict the effect of certain macroeconomic changes on the correlation between stock markets.

This study is an attempt to answer these questions surrounding emerging stock markets. Section 2 gives an overview of the literature on stock market interdependence. The theory of stock market interdependence is explained in Section 3 and in Section 4 a regression model is used to empirically determine the factors that influence the extent of emerging stock market interdependence. The forecasting ability of this model is compared with that of three atheoretical models in Section 5, and Section 6 presents the conclusions drawn from this study.

\section{Literature review}

The literature on stock market interdependence can be divided into three categories. The first category is studies that simply examine stock market interrelations to determine how 
interdependent a specific group of stock markets are. The second category goes beyond this and examines possible changes in stock market relationships. This includes studies that simply compare pre- and post-crisis relationships, as well as studies that examine the evolution of stock market relationships over time. The third and last category is studies that try to explain why stock markets are interdependent, by either decomposing or modeling stock market correlations.

Most of the studies on stock market interdependence in emerging markets have been done on geographical groups of markets, such as in the Asian or Latin American countries. Stock market interdependence in the emerging markets in Asia seems to be a widely accepted fact. Masih and Masih (1999) found a high level of interdependence among the stock markets of Thailand, Malaysia, the US, the UK, Japan, Hong Kong and Singapore from 1992 to 1997. Consistent with their later findings (Masih and Masih, 1999), Masih and Masih (1997) found a high level of interdependence among the markets of Taiwan, South Korea, Singapore, Hong Kong, the US, the UK, Germany and Japan for 1982 to 1994.

Other authors examined different groups of Asian markets, but their results are consistent with those of Masih and Masih (1997, 1999), since they all found their respective stock market groups to be interdependent. Palac-McMiken (1997) found cointegration in the monthly ASEAN markets (Indonesia, Malaysia, the Philippines, Singapore and Thailand) during the period 1987 to 1995. Chowdhury (1994) used variance decomposition and impulse response functions to examine the relationships among the Asian Newly Industrialized Economies (NIEs), Japan and the US, using daily data for the period January 1986 to December 1990. He found that the US led the NIEs and that there were significant linkages between the markets. In general, these studies used different techniques and different sample periods, but they all found that the emerging Asian markets are interdependent.

Although there is substantially less literature on stock market interdependence in the emerging Latin American markets, all the available results indicate that the stock markets in this region are also interdependent. Christofi and Pericli (1999) found a high level of interdependence among the stock markets of Argentina, Brazil, Chile, Columbia and Mexico from 1992 to 1997. Likewise, Choudhry (1997) found interdependence among the stock markets of Argentina, Brazil, Chile, Colombia, Mexico and Venezuela. Therefore, consistent with the results of the emerging Asian markets, the emerging Latin American markets are found to be interdependent. However, the relationship between the emerging Latin American markets and other markets is, once again, not addressed.

Although stock market interdependence within the Asian and Latin American regions is a wellestablished fact, it is uncertain whether these results will also hold true for other regions. In addition, the extent of interdependence between emerging stock markets in different regions has to be examined in order to verify whether all emerging stock markets are interdependent or whether stock market interdependence is a purely regional effect.

The October 1987 stock market crash not only drew a lot of attention to the interrelationships 
between stock markets, but also raised the question of whether these relationships are stable over time. Several studies examined the effect of the 1987 crash on the interrelationships between emerging stock markets. However, most of them simply tested an instantaneous break at the time of the crash and very few considered the possibility of a more gradual change.

Liu et al. (1998) examined the stability of the relationships among the emerging and developed Asian markets of Thailand, Taiwan, Japan, Singapore, Hong Kong and the US by dividing their sample into two subsamples: 2 January 1985 to 16 October 1987, and 19 October 1987 to 31 December 1990. They found an increase in the general stock market interdependence as well as an increase in the interdependence within the Asian-Pacific regional markets after the 1987 crisis. Likewise, Arshanapalli et al. (1995) found an increase in stock market interdependence after the 1987 crisis for the developing markets of Malaysia, the Philippines, Thailand and the developed markets of Hong Kong, Singapore, the US and Japan for the period 1986 to 1992. They defined the pre-crash period as January 1986 to September 1987 and the post-crash period as November 1987 to December 1992. They found cointegration in the post-crash period, but not in the pre-crash period and concluded from this that that stock market cointegration had increased after the October 1987 crash.

Instead of the 1987 stock market crash, Sheng and Tu (2000) examined the stock market relationships of the following emerging and developed Asian-Pacific countries before and during the period of the 1998 Asian financial crisis: Taiwan, Malaysia, Thailand, South Korea, the Philippines, Indonesia, China, the US, Australia, Singapore, Japan and Hong Kong. They used daily data for the period 1 July 1996 to 30 June 1998, and split it on 30 June 1997 to create pre- and post-crisis samples. They found that stock market interdependence has increased since the crisis. The conclusion of Sheng and Tu (2000) on the effect of the 1998 crisis is consistent with those reached by Arshanapalli et al. (1995) and Liu et al. (1998) for the 1987 crash. This means that the possibilities for international diversification are lower during a crisis when they are needed most.

All the studies examining the effect of a crisis on stock market relationships used different approaches with respect to the division of the sample period. Some simply split the total sample period into two, while others completely excluded the month or week of the crisis itself. Since the exact beginning and end of a crisis is generally undeterminable, there is no clear-cut rule on how to split a sample. All these studies have shown that the relationships are influenced by a crisis, which means that they are not constant over time and therefore the results may not be robust with respect to the choice of sample period. Arshanapalli and Doukas (1993) tested the effect of including or excluding the data for the crash period (October 1987). Their findings indicated that the degree of stock market co-movement was so high during the crisis that the inclusion or exclusion of the crash period dramatically influences the empirical results. This means that the results are not robust with respect to the choice of how to incorporate the break period into the tests.

Their warning was echoed by Meric and Meric (1989), who showed that stock market relationships are not stable over time, which means that the choice of sample period may influence the results of 
stock market interdependence analyses. In other words, stock market relationships are not stable over time and the decision on where to split the sample in the event of a crisis, influences the results significantly. In addition, a stock market crisis is not the only potential factor that can influence stock market interrelationships over time. There are several other variables that potentially have an influence on stock market interrelationships and, to the extent that these factors influence stock market relationships, they can cause changes in the relationships over time. The best way to get around this dangerous pitfall is to avoid splitting the sample period altogether and rather to study the evolution of the relationships over time. It will, in any case, be of much more interest to see how stock market interrelationships evolve, rather than to simply compare pre- and post-crisis results.

Smith et al. (1993) looked at how stock market relationships evolve over time. They used rolling Granger (1969) causality tests to illustrate and examine the changes in the relationships of the US, the UK, West German and Japanese stock market relationships from 1979 to 1991. They found Granger causality in the period surrounding the crash, but other than in the crash period, there was a lack of significant causal relationships. This led them to conclude that gains from international diversification are still obtainable and that the crash had altered stock market relationships. However, they did not try to explain why these relationships evolve over time.

Even though stock market interdependence seems to be a widely accepted fact, the literature explaining why stock markets are interdependent is quite sparse. Most studies that do address this issue, concentrate on decomposing stock returns into country and industry effects and very few examine the other economic variables that may drive stock market co-movement.

Roll (1992) decomposed individual stock returns into country and industry components. He found that the industry component is significant, which means that stocks from different countries, but from the same industry, are correlated. Therefore, countries whose stock markets are similar in terms of industry composition will be interdependent.

While the results of Roll (1992) showed that industry composition is significant in explaining stock market correlation, Serra (2000) reached the opposite conclusion. Serra decomposed the individual stock returns from several emerging markets and found that country effects are the most important factors driving the behavior of emerging markets' individual stock returns. In contrast to Roll, she found that emerging market indices are driven by country factors and cross-market correlation does not seem to be affected by the industrial composition of the indices. She also found that regional factors only play a small role. Even within one region, local rather than regional effects drive the constituent markets. Serra's results are consistent with the findings of Rouwenhorst (1999), who found that the country composition of a portfolio is more important than its sector composition.

Chen and Zhang (1997) attempted to explain the extent of stock market correlation with the extent of bilateral trade. They calculated the correlations between the emerging stock markets of Korea, Malaysia, Thailand, Taiwan, the Philippines and Mexico, and the developed markets of the 
US, Hong Kong, Japan, Canada, Singapore, Australia, New Zealand, Austria, Belgium, Denmark, France, Germany, Italy, the Netherlands, Norway, Spain, Sweden, Switzerland and the UK They divided the world into four regions: the US, Europe, Japan and the Asian Newly Industrialized Economies (NIEs). They calculated each country's correlation with each region, and then tried to determine whether these correlations can be explained by the extent of bilateral trade between the country and the region. Overall, they found that stock market interdependence is positively correlated with the extent of trade. The extent of trade explains between 5 and $40 \%$ of the variation in the correlation, depending on the measure of correlation used. Consistent with the results of Chen and Zhang (1997), Bekaert and Harvey (1997) found that trade is important in explaining equity correlations specifically in the emerging market context.

Whereas Chen and Zhang (1997) simply used the extent of bilateral trade, Bracker et al. (1999) also took other economic variables into account. In addition, they tried to explain why stock market relationships evolve over time and used the measures of feedback of Geweke (1982) to determine the extent of stock market interdependence. The Geweke test statistics were then regressed on macroeconomic variables in a pooled model. The results indicated that imports, the size differential, the physical distance between markets, a trend and different intercepts for each region were significant, whereas exports, the inflation differential, the interest rate differential, the percentage change in the exchange rate, and the volatility of the exchange rate were not significant. They also used this economic model and three atheoretical models to forecast the correlation structure, and their economic model outperformed the atheoretical models in terms of forecasting ability as evaluated by the root mean square error (R.M.S.E.).

In a similar study, Bracker et al. (1999) used daily returns to construct a quarterly time series of the correlation matrix and found substantial changes over time in this matrix. They regressed the correlation matrices on the following economic variables: differentials in industrial production growth (Dumas et al, 2001), ${ }^{1}$ inflation, real interest rate, term structure premium and share in total world capacity; absolute changes and volatility in the bilateral exchange rate; variability in the world equity index; a non-linear trend; dummies for October 1987 and 1989; seasonal dummies; and bilateral trade. They found that the degree of international interdependence as measured by the magnitude of correlation is a positive function of market volatility and a trend, and a negative function of exchange rate volatility, term structure differentials, real interest rate differentials, and the return on the world market index.

It is clear from the literature that stock markets, in particular emerging stock markets, are interdependent. However, the factors that drive this interdependence are still largely unexplored in the case of emerging stock markets. The factors that have been shown to significantly influence the extent of integration among developed stock markets are: industrial composition, bilateral trade, size

\footnotetext{
${ }^{1}$ Dumas, Harvey and Ruiz (2001) showed that correlations of GDP growth rates could be mapped into equity correlations.
} 
differential, physical distance, regional effects, market volatility, exchange rate volatility, term structure differentials, real interest rate differentials and the return on the world market index. It might be completely different factors that drive integration in emerging stock markets, since it is well known that equities from emerging markets have vastly different characteristics than equities from developed markets (Bekaert and Harvey, 1997). In this study, the influence of these and other factors on the extent of integration between emerging stock markets will be evaluated.

\section{The theory of stock market interdependence}

In general, there are three categories of explanations as to why there is co-movement among different stock markets. The first category is the so-called 'contagion' effect, which is the part of stock market co-movement that cannot be explained by economic fundamentals. The second category is economic integration, which means that the more the economies of two countries are integrated, the more interdependent or integrated their stock markets will be. Economic integration includes not only trade relationships, but also co-movement in the economic indicators that influence stock market returns, such as interest rates and inflation. The third and last category includes stock market characteristics that influence the extent of stock market interdependence, namely industrial similarity, volatility and market size.

\subsection{Contagion}

'Contagion', as defined by the academic profession, is the co-movement of asset markets not caused by a common movement of fundamentals (Wolf, 1998). Contagion is not measurable in itself, but rather estimated with the residual from the co-movement that is not explained by fundamentals. There are two broad categories of literature on this field, either based on informational factors or based on institutional factors (Wolf, 1998). The category of informational factors is based on the wellknown comparison between the stock market and the Keynesian 'beauty contest'. In the Keynesian beauty contest, each judge votes the way he thinks the other judges will vote. In the same way, investors will sell their investments in a specific asset class if they believe that other investors will sell their investments in that asset class. This provides some explanation of the herd behavior of stock market traders, which leads to a sell-off of emerging market securities if a sufficient number of investors believe that other investors have become disenchanted with the 'emerging markets' asset class. The herd behavior of investors will lead to a widespread decline or upswing in emerging markets and if this widespread movement is not caused by fundamentals, it is, by definition, 'contagion'.

However, this does not explain why investors treat emerging markets as a single class of assets rather than evaluating them individually. One explanation as to why emerging markets are seen as a single 
single asset class, is the principal-agent problem in asset management, whereas another Keynesian observation holds that it is better to fail conventionally than to succeed unconventionally (Scharfstein and Stein, 1990; Grinblatt et al., 1995). When the performance of individual asset managers is compared with that of the market average, low returns shared with most other managers carry little penalty relative to an ex-post, unsuccessful pursuit of an unorthodox strategy. Given the reward structure, even managers of above-average quality may opt to hide in the herd rather than follow strategies that may dominate on a risk-return basis. Applied to emerging markets, the principal-agent problem may thus lead to correlated withdrawals, even if some managers are confident about fundamentals (Wolf, 1998).

The category of institutional factors focuses on issues such as forced redemption and two-stage investment strategies (Wolf, 1998). A substantial proportion of the inflows to the equity markets of emerging countries comes through open-ended mutual funds. When these funds are faced with large-scale withdrawals or a reduction in inflows, they may be forced into redemption. Global mutual funds will then sell off their assets in the most liquid markets. In other words, if these markets were not affected previously, they will be affected by the forced redemption. This redemption thus creates a contagion effect in which several markets decline simultaneously without justifying changes in fundamentals. The same occurs when global mutual funds try to exploit perceived mispricing via purchases in the most downtrodden markets, financed through sales of equities in less-affected markets (Wolf, 1998).

With two-stage strategies, some fraction of the overall portfolio is allocated to the 'emerging market' category and is then sub-allocated according to some index weighting. This provides the second of the institutional explanations for contagion to the extent that first-stage decisions, even if motivated by factors relevant to some emerging markets, may also affect markets for which these factors are of little importance (Buckberg, 1996; Chuhan, 1994).

\subsection{Economic integration}

From a macroeconomic perspective, there are two broad categories of economic variables that influence the degree of stock market interdependence. First, the extent to which two economies depend on each other will influence the extent to which their stock markets are interdependent. In other words, the stronger the bilateral trade ties between two countries, the higher the degree of comovement should be between their stock markets. Second, according to the cash flow model, several macroeconomic variables, e.g. interest rates and inflation, influence stock market performance. Since these variables influence stock market returns, the correlation between them will influence the correlation between their stock markets. To the extent that these macroeconomic variables in two countries are the same, their stock market performance should be the same. Similarly, over time, to the extent that these macroeconomic variables in two countries are convergent (divergent), their stock market performances should converge (diverge) as well. 


\subsubsection{Bilateral trade}

When two countries have a strong bilateral trade relationship, their economies and stock markets are expected to be highly interdependent. If a substantial proportion of country A's total exports are exported to country B, then a downswing in country B will cause a decline in its imports from country A. There will be a decline in country B's stock market associated with the domestic downswing in country $\mathrm{B}$ and at the same time a decline in country A's stock market due to the reduction in exports to country B. The stock markets of the two countries will thus exhibit a co-movement due to their bilateral trade ties. The more important the trade ties, the higher the degree of co-movement in the stock markets should be. Therefore, the bilateral trade relationship between two countries is expected to explain some of the correlation or co-movement between their stock markets.

\subsubsection{The cash flow model}

Stock prices $(P)$ can be written as the expected discounted stream of dividends:

$$
P=\frac{(1+g) D_{0}}{k-g}
$$

where $D_{0}$ is the last dividend paid, $g$ is the (constant) growth rate in dividends and $k$ is the discount rate.

It follows trivially that the systematic forces that influence stock prices, and hence returns, are those that influence the discount factors, $k$, or growth rate in dividends, $g$. Any factor that influences the stream of cash flows or the discount rate will systematically influence stock prices. Since the seminal article by Chen et al. (1986), the influence of interest rates and inflation on the discount rate, and of the industrial production growth on the expected cash flows - and hence on stock prices - has been well established.

These macroeconomic variables influence the stock market performance of an individual country, which means that in two countries in which these variables are similar, the stock market performance will be similar. For example, if the interest rates of two countries show the same trend over time, perhaps due to similar monetary policies, the effect of interest rates on stock prices will cause a comovement in the two stock markets. Therefore, larger interest rate, growth and inflation differentials will cause a smaller amount of co-movement. It is expected that, over time, increasing deviations will cause less stock market co-movement. To the extent that any of the economic variables that influence stock markets in two countries diverge (converge), their stock prices are expected to diverge (converge).

\subsection{Stock market characteristics}

Apart from the economic variables discussed in the previous section, several other variables have been discussed in the literature as having the potential to influence the extent of stock market correlation. These factors are stock market size, stock market volatility and industrial similarity. 


\subsubsection{Size}

The effect of the size of a firm on its stock market performance is a well-documented phenomenon (see for example Banz, 1981; Berk, 1996; Keppler and Traub, 1993; Asness et al., 1996). Smaller firms command higher returns, due to less liquidity and the higher transaction costs associated with trading their equity. By extension, the size of a national equity market may reflect its stage of development, and may also indicate the degree of market liquidity and the level of information cost and transaction cost associated with trading equity in that market. From this perspective, a large disparity in market sizes may indicate large differences in the liquidity, information costs and transaction costs between the two markets, which should result in less co-movement. Over time, as the size differential of the two stock markets increases (decreases), the extent of their co-movement will decrease (increase).

\subsubsection{Volatility}

The basic principle on which all investment models are based is that investors should be compensated for the risk they take on, in other words the higher the risk of an asset the higher its returns should be. This means that the returns on any asset should be a positive function of its risk, where risk is often measured by volatility. Since the return of any stock market is a function of its volatility, two markets with more or less the same volatility should yield more or less the same returns. Therefore, if one market's volatility increases relative to another market's volatility, the first market's returns should increase relative to the second market's returns. Therefore, to the extent that stock market volatilities converge (diverge), their stock prices should converge (diverge).

\subsubsection{Industrial similarity}

The effect of industrial similarity on stock market correlation has received a substantial amount of attention in the literature (e.g. Serra, 2000; Wolf, 1998; Roll, 1992). The performance of any index is partly determined by sectoral composition and partly obscured by idiosyncratic noise (Wolf, 1998). For example, consider two emerging market indices dominated by equities in a single sector, say petroleum. A decrease in the world demand for oil may lead to a substantial decrease in the equity prices of oil companies in both economies. Thus, when two markets are both dominated by the same type of industry their stock markets will reveal co-movement, to the extent that the general performance of their stock markets is based on that industry. This does not only happen in the extreme case when two markets are dominated by the same sector, but also in general the extent of industrial similarity between the two stock markets increase the extent of their co-movement.

\section{Modeling of stock market interdependence}

In this section, the influence of each of these factors will be estimated empirically. The analysis will be carried out in two parts. In the first part, a cross-sectional analysis will be done in which all the 
pairwise simple correlations from the first quarter of 1995 to the third quarter of 2000 will be pooled across all the country pairs and regressed on the averages of the possible explanatory variables. This will explain why stock markets are correlated and it will also show how much of the correlations can be explained, which is an upper bound on the extent that these correlations can be due to contagion.

In the second part, a time-series approach will be followed to explain why the relationships change over time. In this model, the simple correlation coefficient for each pair of countries will be calculated for each quarter, from the first quarter of 1995 to the third quarter of 2000. The quarterly correlation coefficients will then be regressed on the average values of the dependent variables for each quarter. Once again all the observations will be pooled across the pairs of countries.

\subsection{Data}

The term 'emerging stock market' refers to a stock market that is in transition, in other words increasing in size, activity or level of sophistication. The term is usually defined by a number of parameters that attempt to assess a stock market's relative level of development and/or an economy's level of development (Standard and Poors, 2000). In this study, the definition of an emerging stock market as given in the Emerging Market Database (EMDB) will be used. In general, EMDB classifies a stock market as 'emerging' if it meets at least one of two general criteria: (i) it is located in a low- or middle-income economy as defined by the World Bank and (ii) its investable market capitalization is low relative to its most recent GNP figures (Standard and Poors, 2000). In other words, a stock market is classified as 'emerging' unless the country's GNP has fallen into the high-income range for 3 consecutive years, and its ratio of investable market capitalization to GNP has fallen into the top $25 \%$ of emerging markets for 3 consecutive years (Standard and Poors, 2000).

The 10 emerging stock markets (according to the EMDB definition) with the highest market capitalization will be used in the analysis. However, Taiwan was excluded from this study since it is not a member of the International Monetary Fund (IMF) and, therefore, comparable data on the economic variables was not available. The 10 remaining stock markets, namely Argentina, Brazil, China, Greece, India, Korea, Malaysia, Mexico, South Africa and Turkey, were used in the analysis. These markets are all in Asia, Latin America, Africa or Europe. Throughout this analysis, Africa and Europe will be considered as one region.

The IFC stock market indices were obtained from Datastream. The data on market capitalization and industry weights were collected from various issues of the Emerging Stock Markets Factbook (published by the International Finance Corporation, 1998, 1999). Inflation, exchange rate and industrial production figures were extracted from various issues of International Financial Statistics published by the IMF. Trade data were obtained from the IMF's Direction of Trade publication. Data for the first quarter of 1995 to the third quarter of 2000 was used. The results of the unit root tests show that all the series are stationary (results omitted for brevity). 


\subsection{Empirical framework}

Section 2 gave an exposition of the theoretical reasons why co-movement between stock markets exists. In general, changes over time in the factors that determine stock market correlation are also the potential determinants of changes in stock market correlation over time. For example, the stock markets in two countries with strong trade ties will be more correlated, and similarly, to the extent that the bilateral trade between the two countries increases, their stock market correlation should increase. Over time, stock market correlation should increase as industrial similarity or bilateral trade increase, or as the macroeconomic variables that influence stock prices converge. The first seven factors, i.e. (i) to (vii), will be included in both the cross-sectional and time-series models, but the last three factors, i.e. (viii) to (x), can only be estimated in a time-series context. A priori theory suggests the following about the relevant variables and their coefficients (see Table 1).

i Trade: the more important the trade relationship between two countries, the more correlated their stock markets should be. Rather than the monetary value or volume of the trade, it is the importance of the trade relationship relative to their other trade relationships that will influence the correlation between their stock markets. Therefore, the sum of the value of bilateral trade as a proportion of each country's total trade will be used, instead of simply the volume or value of the bilateral trade.

ii Inflation differentials: since inflation influences stock prices, the inflation differential of two countries is expected to influence the extent of interdependence between their stock markets negatively. If their inflation rates converge (diverge), this will force their stock markets in the same (different) direction. Since correlation does not involve a direction of causality, it is necessary to use the absolute value of the inflation differential as it does not matter which country's inflation rate is higher, but only how large the difference is. Therefore, the absolute value of the inflation differential should have a negative impact on stock market correlation.

iii Industrial production growth: industrial production growth influences stock market behavior through the cash flow model. Therefore, the absolute value of the difference between two countries' industrial production growth rates will be negatively correlated with the extent of their stock market correlation.

iv Interest rates: interest rates influence the discount factor of the cash flow model and hence, stock prices. Therefore, the interest rate differential between two countries should be negatively correlated with their stock market correlation. Once again, it is the absolute value of the differential, and not the actual difference, that is important. 
Table 1

List of variables

\begin{tabular}{ll}
\hline Variable & Description \\
\hline Cor $_{i j}$ & Correlation between daily rate of return of countries $i$ and $j$ \\
Trade $_{i j}$ & $\frac{x_{i j}+z_{i j}}{X_{i}+Z_{i}}+\frac{x_{j i}+z_{j i}}{X_{j}+Z_{j}}$ where $z_{i j}$ and $x_{i j}$ are imports and exports from country $i$ \\
& to country $j . X_{i}$ and $Z_{i}$ are the total exports and imports of country $i$ \\
Industrial & Sum of absolute differences between the weight of each sector in \\
\multicolumn{1}{c}{ dissimilarity } \\
$\pi_{i j}$ & countries $i$ and $j$ \\
$r_{i j}$ & Inflation differential between countries $i$ and $j$ \\
Growth $_{i j}$ & Interest rate differential between countries $i$ and $j$ \\
Size $_{i j}$ & Industrial growth differential between countries $i$ and $j$ \\
Vol $_{i j}$ & Size differential between countries $i$ and $j$ \\
Trend $_{t}$ & Ratio of the variances of the returns in countries $i$ and $j$ \\
Qi $_{t}$ & Dummy: equals $t$ in quarter $t$ \\
Dum $-1998_{t}$ & Dummy: equals 1 in quarter $i$, otherwise 0, for $i=1,2,3$ \\
Dum $-1998 s_{t}$ & Dummy: takes on the value 1 in 1998, otherwise 0 \\
Dum - region $_{i j}$ & Dummy: equals 0 before 1998 quarter 1,1 otherwise \\
Dum $-\mathrm{LA}_{i j}$ & Dummy: equals 1 if the countries are in the same region, 0 otherwise \\
Dum $-\mathrm{EA}_{i j}$ & Dummy: equals 1 if both countries are in Latin America, 0 otherwise \\
Dum - Asia $_{i j}$ & Dummy: equals 1 if both countries are in Africa or Europe, 0 otherwise \\
\hline
\end{tabular}

v Size: since the size of a stock market reflects its liquidity and transaction costs, and therefore, influences stock prices, the absolute value of the size difference between any countries' stock markets will have a negative relationship with the correlation of their stock markets.

vi Volatility: the risk of a stock market is measured by its volatility and stock prices are positively influenced by volatility, since investors demand higher returns for tolerating higher risk. This means that in two stock markets whose volatilities converge (diverge), the prices should also converge (diverge). Therefore, the correlation between two stock markets should be a negative function of the ratio of their volatilities.

vii Region: stock markets within a region can be interdependent due to policy coordination or simply due to contagion caused by investors' treatment of the asset markets within a region as one asset class. Therefore, the correlation between two countries that are in the same region is expected to be higher than that of two countries in different regions.

viii Trend: stock market correlations are expected to increase over time due to increasing globalization, continuous improvements in communication and information technology, and the ongoing relaxation of foreign exchange and other controls by emerging countries. The coefficient of the time trend should therefore have a positive sign.

ix Quarterly effect: since several authors have found a quarterly effect in stock market returns, as well as in stock market correlations, dummy variables will be used to test whether the correlations between emerging markets have a quarterly component. 

different during the crisis, while the second dummy will test whether there was a structural break at the time of the crisis.

The time-series model is similar to the cross-section model in that it simply takes the values in each quarter instead of averages. The time-series approach makes it possible to test some additional factors, namely a time trend, a quarterly effect and the effect of the 1998 emerging market crisis. Due to the limited number of observations within each region in the cross-sectional analysis, it is more appropriate to simply test for a different intercept between and within regions. For example, there are only three observations for which both countries are in the Latin American region. However, in the time-series model, there are enough degrees of freedom to allow a different intercept for each region.

\subsection{Cross-section model}

The results of the OLS estimation are given in Table 2, with both the usual and White (1980) standard errors, $t$-statistics and probability values for the coefficients, with the White values being indicated by a subscript, $\mathrm{W}$.

Only the extent of bilateral trade, industrial production growth differentials and a dummy to test the regional effect were significant in explaining the pairwise correlation coefficients. All the other potential explanatory variables were insignificant and were consequently dropped from the model. The probability values given in Table 2 are for testing relevant one-sided hypotheses, in other words for testing the null hypothesis that the coefficient equals zero against the alternative that the coefficient is greater than zero (or less than zero in the case of the growth differential), except for the intercept where the two-sided hypothesis has to be tested, since there is no a priori theory regarding its sign. The estimated coefficients can be interpreted as follows.

Table 2

Results of cross-section regression of pairwise correlation coefficients

\begin{tabular}{lrlrllrl}
\hline Variable & Cocff. & S.E. & $t$-statistic & $P$ & S.E. & $t$-statistic & $P_{\mathrm{W}}$ \\
\hline Dum - region & 0.17649 & 0.03603 & 2.43580 & 0.0095 & 0.05521 & 1.58949 & 0.05980 \\
Trade & 0.81383 & 0.28663 & 2.83935 & 0.0035 & 0.40129 & 2.02803 & 0.02455 \\
Growth & -1.27915 & 0.97265 & -1.31512 & 0.0979 & 0.80212 & -1.59471 & 0.05925 \\
C & 0.08872 & 0.01908 & 4.64945 & 0.0000 & 0.01284 & 6.91130 & 0.00000 \\
$R^{2}$ & & & & & & & \\
Adjusted $R^{2}$ & 0.370684 & & & $F$-statistic & 8.05 & & \\
\hline
\end{tabular}


i Trade: the pairwise correlation coefficient between two stock markets will increase by 81.383 basis points for every unit increase in the average trade ratio, which is calculated as the sum of each country's average quarterly trade with the other country as a percentage of its total average quarterly trade.

ii Growth: for every unit increase in the industrial production growth differential between two countries, their correlation coefficient will decrease by 127.915 basis points.

iii Dum - reg: the correlation coefficients of stock markets in the same region are on average 17.649 basis points higher than the average correlation coefficient of stock markets in different regions.

Economic theory provides a priori information only on the signs of the coefficients and not on their magnitudes. The results in Table 2 indicate that the influence of all the variables conforms to the requirements of economic theory. It can, therefore, be concluded that this function is an acceptable model from an economic point of view.

The usual and White $t$-statistics for testing the significance of the individual coefficients indicate that all the coefficients are significantly different from zero at a $10 \%$ level of significance and should therefore be included in the function. The $R$-square $\left(R^{2}\right)$ of 0.370684 indicates that 37.0684 percent of the variation in the correlation coefficients is explained by the variation in the dependent variables, which is evidence of a reasonably good fit. The F-statistic of 8.05 indicates that the dependent variables are jointly significant in explaining the long-term interest rate. Table 3 summarizes the results of the diagnostic tests performed on the residuals. These diagnostic tests proved that the error terms are normally distributed, homoscedastic and not autocorrelated.

\subsection{Time-series model}

Following Bracker and Koch (1999), the data is pooled and then the pooled pairwise correlation coefficients are regressed on the explanatory variables. All the coefficients, except the intercepts of the different regions, are restricted to being the same for each pair of countries. The theoretical

Table 3

Diagnostic tests

\begin{tabular}{llll}
\hline Test performed for: & Test & Test-statistic & Conclusion \\
\hline Normality & Jarque-Bera & 0.27 & Residuals normally distributed \\
Heteroscedasticity & ARCH & 0.089 & Residuals are homoscedastic \\
& White & 2.826 & Residuals are homoscedastic \\
Serial correlation & Breusch-Godfrey & 1.58 & No serial correlation \\
& Durbin Watson & 1.94 & No serial correlation \\
\hline
\end{tabular}

\footnotetext{
${ }^{a}$ Statistically significant on a $10 \%$ level.

${ }^{\mathrm{b}}$ Statistically significant on a $5 \%$ level.

${ }^{\mathrm{c}}$ Statistically significant on a $1 \%$ level.
} 
Table 4

Results of time-series regression of pairwise correlation coefficients

\begin{tabular}{lclclcrc}
\hline Variable & Coeff. & S.E. & $t$-statistic & $P$ & S.E.W $_{\cdot}$ & t-statistic $_{\mathrm{NW}}$ & $P_{\mathrm{NW}}$ \\
\hline Growth & -0.41299 & 0.06786 & -6.08612 & 0.0000 & 0.05663 & -7.29316 & 0.0000 \\
Trade & 0.16981 & 0.09860 & 1.72226 & 0.0427 & 0.11358 & 1.49501 & 0.0676 \\
Dum - LA & 0.44223 & 0.02344 & 18.8654 & 0.0000 & 0.03571 & 12.3840 & 0.0000 \\
Dum - EA & 0.11597 & 0.01981 & 5.85402 & 0.0000 & 0.02248 & 5.15929 & 0.0000 \\
Dum - ASIA & 0.05611 & 0.01651 & 3.39837 & 0.0004 & 0.01872 & 2.99654 & 0.0014 \\
D98 & 0.10516 & 0.01222 & 8.60418 & 0.0000 & 0.01250 & 8.41333 & 0.0000 \\
C & 0.05577 & 0.01053 & 5.29631 & 0.0000 & 0.01112 & 5.01745 & 0.0000 \\
$R^{2}$ & 0.39949 & & & $F$-statistic & & 97.60167 & \\
Adjusted $R^{2}$ & 0.39540 & & & $P(F$-statistic $)$ & & 0.000000 & \\
\hline
\end{tabular}

model in Section 4.2 was empirically estimated using quarterly data for all 10 countries, from the first quarter of 1995 to the third quarter of 2000.

The results of the OLS estimation are given in Table 4, with both the usual and Newey-West (Newey and West, 1987) standard errors, $t$-statistics and probability values for the coefficients, with the Newey-West values being indicated by a subscript, NW.

Only the extent of bilateral trade, industrial production growth differentials and a dummy to reflect the 1998 emerging market crisis were significant in explaining the pairwise correlation coefficients. In addition, all three regional dummies are significant, which means that stock markets in the same region have a higher correlation than stock markets in different regions. All the other potential explanatory variables were insignificant and were consequently dropped from the model. The probability values given in Table 4 are for testing relevant one-sided hypotheses, in other words testing the null hypothesis that the coefficient equals zero against the alternative that the coefficient is greater than zero (or less than zero in the case of the growth differential). The estimated coefficients can be interpreted as follows.

i Trade: the pairwise correlation coefficient between two stock markets will increase by 16.9808 basis points for every unit increase in the trade ratio, which is calculated as the sum of each country's trade with the other country as a percentage of its total trade.

ii Growth: for every unit increase in the industrial production growth differential between two countries, their correlation coefficient will decrease by 41.2993 basis points.

iii Dum - 1998: the correlation coefficients were on average 10.5161 basis points higher than usual during the 1998 emerging market crisis.

iv Dum - LA: on average, if both stock markets are in Latin America, their correlation will be 44.2229 basis points higher than that between two markets in different regions. 
v Dum -Asia: on average, the correlation between two Asian stock markets is 5.6101 basis points higher than that between two markets in different regions.

vi Dum - EA: the correlation coefficient of stock markets in the African-European region is on average 11.5970 basis points higher than that between two markets in different regions.

Economic theory provides a priori information only on the signs of the coefficients and not on their magnitudes. The results in Table 4 indicate that the influence of all the variables conforms to the requirements of economic theory. It can, therefore, be concluded that this function is an acceptable model from an economic point of view.

Since all the variables in the regression are stationary, the assumptions of classic regression analysis are fulfilled. Consequently, standard diagnostic and other statistical tests can be used to evaluate this function statistically. The usual and Newey-West $t$-statistics for testing the significance of the individual coefficients indicate that all the coefficients are significantly different from zero at a $10 \%$ level of significance, and should therefore be included in the function.

The $R$-square $\left(R^{2}\right)$ of 0.399490 indicates that $39.9490 \%$ of the variation in the correlation coefficients is explained by the variation in the dependent variables, which is evidence of a reasonably good fit, since similar studies on developed stock markets had correlation coefficients of only up to 0.44 . The F-statistic of 97.60167 indicates that the dependent variables are jointly significant in explaining stock market correlations. Table 5 summarizes the results of the diagnostic tests performed on the residuals. These diagnostic tests proved that the error terms are normally distributed, homoscedastic and not autocorrelated.

\section{Forecast comparison}

The economic models of Section 4 made a contribution to the literature by establishing the factors that determine the extent of interdependence between emerging stock markets. In addition,

Table 5

Diagnostic tests

\begin{tabular}{llll}
\hline Test performed for: & Test & Test-statistic & Conclusion \\
\hline Normality & Jarque-Bera & 0.22 & $\begin{array}{l}\text { Residuals are normally } \\
\text { distributed }\end{array}$ \\
Heteroscedasticity & ARCH & 1.28 & Residuals are homoscedastic \\
& White & 1.28 & Residuals are homoscedastic \\
Serial correlation & Breusch-Godfrey & 0.45 & No serial correlation \\
& Durbin Watson & 1.97 & No serial correlation \\
\hline
\end{tabular}

${ }^{\text {a }}$ Statistically significant on a $10 \%$ level.

${ }^{\mathrm{b}}$ Statistically significant on a $5 \%$ level.

${ }^{\mathrm{c}}$ Statistically significant on a $1 \%$ level. 
the time-series model can be used to make forecasts of the correlation coefficients. This will enable policy-makers and investors to analyze different scenarios and to predict the effect of certain macroeconomic changes on the correlation between stock markets. For example, if trade between two countries is expected to increase during the following quarter, the model can be used to predict the effect of the two stock markets involved. However, this means that some prediction of the increase or the value of bilateral trade must be made. If the actual values of the interdependence during the forecasting period are used, this gives the economic model an unrealistic benefit. Therefore, a very conservative approach will be followed with respect to the economic model. Instead of using the actual values of the explanatory variables during the forecasting period, the latest available values at the time of the forecast will be used. This is a very conservative approach and any improvement in the forecasts of the explanatory variables will obviously improve the forecasting ability of the model for the correlation coefficients. To test the forecasting ability of this model, it will be compared with that of three atheoretical forecasting models.

\subsection{Forecasting models}

The forecasts of the economic model are calculated by using the conditional expectations of the model presented in Section 4. Assuming that the relationships also hold in period $t+1$, and using the conditional expectations, the one-step-ahead forecasts of the economic model are as follows:

$$
\begin{aligned}
E\left[\left(\operatorname{cor}_{i j}\right)_{t+1} \mid I_{t}\right]= & 0.055768+0.652070 * E\left[\left(\operatorname{Trade}_{i j}\right)_{t+1} \mid I_{t}\right] \\
& -0.264940 * E\left[\left|\operatorname{growth}_{j}\right|_{t+1} \mid I_{t}\right]+0.107113 * \text { Dum } \\
& -1998+0.442229 * \text { Dum }-\mathrm{La}_{i j}+0.11597 * \text { Dum }-\mathrm{EA}_{i j} \\
& +0.056101 * \text { Dum }- \text { Asia }_{i j}
\end{aligned}
$$

where $E\left[X_{t+1} \mid I_{t}\right]$ is the expected value of variable $X$ in period $t+1$, conditional on the information available in period $t$.

In order to obtain forecasts of the correlation coefficients from this regression model, the actual value of each explanatory variable in period $t$ is taken as its conditional expectation for period $t+1$.This is a conservative approach suggested by Bracker and Koch (1999) for implementing the economic model to generate forecasts. The approach would be appropriate, for example, if each righthand-side macroeconomic variable followed a random walk.

The forecasting ability of the economic model will be compared with that of three atheoretical models. The first atheoretical model is a one-step-ahead forecast of no change from the previous quarter's observation on the correlation matrix. This naive model may seem like a weak challenge, but McNees (1992) showed that it performs well in predicting many economic variables. The second model uses the historical average of the series for the one-step-ahead forecast. 
The third atheoretical model is an ARMA (autoregressive moving average) model for each pairwise correlation. A unique ARMA $(p, q)$ model is estimated for each pairwise correlation. In other words, a model of the form:

$$
\begin{aligned}
\left(\operatorname{Cor}_{i j}\right)_{t}= & \mu+\gamma_{1}\left(\operatorname{cor}_{i j}\right)_{t-1}+\gamma_{2}\left(\operatorname{cor}_{i j}\right)_{t-2}+\cdots+\gamma_{p}\left(\operatorname{cor}_{i j}\right)_{t-p}+\varepsilon_{t}+\theta_{1} \varepsilon_{t-1} \\
& +\theta_{2} \varepsilon_{t-2}+\cdots+\theta_{q} \varepsilon_{t-q}
\end{aligned}
$$

is estimated for each of the 45 pairwise correlation coefficients, where $p$ and $q$ are uniquely determined for each model.

Both $p$ and $q$ were only allowed to be a maximum of two, as suggested by Greene (1993). If a model has been specified correctly, the residuals should resemble a 'white noise process' (Pindyck and Rubinfeld, 1991). Diagnostic tests indicated that the residuals of all the models are normally distributed, homoscedastic and not autocorrelated, which means that they are white noise and that the models are good enough to use for forecasting (results omitted for brevity).

\subsection{Forecasting results}

The performance of these four models is evaluated on the basis of the root mean squared error (R.M.S.E.), the root mean square percentage error (R.M.S.P.E.) and Theil's inequality coefficient (U) across the set of forecasts for every quarter. Table 6 presents the R.M.S.E., R.M.S.P.E. and $U$ and the decomposition of $U$ for each forecasting model across the 45 correlation forecasts.

The economic model performs relatively well in forecasting the correlation coefficients, having the lowest R.M.S.E. and U. However, it does not have the lowest R.M.S.P.E. The ARMA model is a very close second-best when judged according to the R.M.S.E. and $U$. However, it should be kept in mind that a unique ARMA model was estimated for each pairwise correlation coefficient, whereas all

Table 6

Evaluation of forecasts

\begin{tabular}{lccccc}
\hline Criterion & Period & Average & No change & Economic & ARMA \\
\hline R.M.S.E. & $2000 \mathrm{Q} 4$ & 0.174604 & 0.174387 & 0.162440 & 0.168196 \\
\multirow{2}{*}{ R.M.S.P.E. } & $2001 \mathrm{Q} 1$ & 0.133469 & 0.172620 & 0.132029 & 0.135612 \\
\multirow{4}{*}{$U$} & $2000 \mathrm{Q} 4$ & 35.27537 & 8.480779 & 46.93761 & 32.40527 \\
& $2001 \mathrm{Q} 1$ & 5.36107 & 4.270991 & 6.179281 & 7.212769 \\
$U^{\mathrm{M}}$ & $2000 \mathrm{Q} 4$ & 0.398703 & 0.381146 & 0.350887 & 0.367143 \\
& $2001 \mathrm{Q} 1$ & 0.334083 & 0.413956 & 0.317297 & 0.325615 \\
$U^{S}$ & $2000 \mathrm{Q} 4$ & 0.085674 & 0.179483 & 0.076840 & 0.035490 \\
& $2001 \mathrm{Q} 1$ & 0.000470 & 0.025931 & 0.011889 & 0.006658 \\
$U^{\mathrm{C}}$ & $2000 \mathrm{Q} 4$ & 0.308023 & 0.093283 & 0.174656 & 0.274050 \\
& $2001 \mathrm{Q} 1$ & 0.352161 & 0.044460 & 0.309478 & 0.260075 \\
& $2000 \mathrm{Q} 4$ & 0.627083 & 0.745883 & 0.769484 & 0.712381 \\
& $2001 \mathrm{Q} 1$ & 0.670085 & 0.951746 & 0.831470 & 0.755843 \\
\hline
\end{tabular}


the coefficients of the economic model (except for the intercepts) were restricted to being the same across all pairwise correlation coefficients. In terms of the decomposition of $U$, the economic and ARMA models also perform better than the other two models.

\section{Conclusion}

The interdependence of emerging stock markets has serious implications for both investors and policy-makers. Investors have increasingly turned to the emerging stock markets in their search for international diversification, but the interdependence between these markets may have reduced the scope for diversification possibilities. At the same time, policy-makers in most emerging economies have gone to great lengths in recent years to open up their economies, especially their financial markets, in the hope of sharing in the benefits and efficiencies of an integrated world financial market. It is therefore crucial to understand to the factors that influence the level of interdependence.

In order to determine which factors influence the correlation between two stock markets, a crosssection and a time-series regression model were estimated using data for the period 1995 to 2000 . The results showed that only the extent of bilateral trade and the industrial production growth differential were significant in explaining the correlation between two countries on a cross-sectional basis. In addition, countries in the same region are more correlated than countries in different regions. The results of the time-series regression showed that only the extent of bilateral trade, industrial production growth differentials, a dummy to reflect the 1998 emerging market crisis and regional dummy variables were significant in explaining the pairwise correlation coefficients. The model explained $40 \%$ of the variation in the correlation coefficients, which means that no more than $60 \%$ of this variation can be due to contagion. However, it is possible that any proportion of the $60 \%$ unexplained variation in the correlation coefficients can be explained by an explanatory variable that has been excluded, so this cannot be interpreted as the proportion of the variation that is due to contagion. The economic model also performed well in terms of its forecasting ability when compared with atheoretical models. This structural model can therefore be used to analyze different scenarios and to predict the effect of certain macroeconomic changes on the correlation between stock markets.

It was shown that a substantial proportion of the interdependence among emerging stock markets could be explained by fundamentals. This means that there is still scope for diversification among emerging stock markets, and that it is possible for investors to calculate and forecast where the best diversification possibilities lie. Likewise, policy-makers are assured that their stock markets are not equally vulnerable to spillovers from all the other emerging stock markets, and they can calculate and predict with which countries their stock markets are more interdependent. The proportion of stock market interdependence that is due to 'contagion' has been proved to be smaller than is widely perceived. 


\section{References}

Asness, C.S., Liew J.M., Stevens R.L., 1996. Parallels between the cross-sectional predictability of stock and country returns. Working paper, Goldman Sachs Asset Management, New York.

Arshanapalli, B., Doukas, J., 1993. International stock market linkages: evidence from the pre- and post-October 1987 period. J. Bank. Finance 17, 193-208.

Arshanapalli, B., Doukas, J., Lang, L.H.P., 1995. Pre- and Post-October 1987 stock market linkages between US and Asian markets. Pacific Basin Finance J. 3, 57-73.

Banz, R.W., 1981. The relationship between return and market value of common stocks. J. Financ. Econ. 9, 3-18.

Bekaert, G., Harvey, C.R., 1997. Emerging equity market volatility. J. Financ. Econ. 43, 29-77.

Berk, J., 1996. An Empirical Re-examination of the relation between firm size and return. Unpublished manuscript, University of British Columbia.

Bracker, K., Koch, P.D., 1999. Economic Determinants of the Correlation Structure Across International Equity Markets. J. Econ. Bus. 51, 443-471.

Bracker, K., Docking, D.S., Koch, P.D., 1999. Economic determinants of evolution in international stock market integration. J. Empirical Finance 6, 1-27.

Buckberg, E., 1996. Institutional Investors and Asset Pricing in Emerging Markets. Working Paper No. 96/2, 1996.

Chen, N., Zhang, F., 1997. Correlations, trade and stock returns of the Pacific-Basin markets. Pacific-Basin Finance J. 5, 559-577.

Chen, N.F., Roll, R., Ross, S.A., 1986. Economic Forces and the Stock Markets. J. Bus. 59, 383-403.

Choudhry, T., 1997. Stochastic trends in stock prices: evidence from Latin American markets. J. Macroecon. 19, 285-304.

Chowdhury, A.R., 1994. Stock Market Interdependencies: Evidence from the Asian NIEs. J. Macroecon. 16, 629-651.

Christofi, A., Pericli, A., 1999. Correlation in price changes and volatility of major Latin American stock markets. J. Multinatl Financ. Manage. 9, 79-93.

Chuhan, P., 1994. Are Institutional Investors an Important Source of Portfolio Investment in Emerging Markets? World Bank, WPS 1243.

Dumas, B., Harvey C.R., Ruiz P., 2001. Are correlations of stock returns justified by subsequent changes in national output? Working paper.

Geweke, J., 1982. Measurement of linear dependence and feedback between multiple time series. J. Am. Stat. Assoc. 77, 304-313.

Granger, C, 1969. Investigating causal relations by econometric models and cross-spectral methods. Econometrica 37, 424-438.

Greene, W.H., 1993. Econometric Analysis. Prentice Hall, New Jersey.

International Finance Corporation, 1998. Emerging Stock Markets Factbook. Washington, International Finance Corporation.

International Finance Corporation, 1999. Emerging Stock Markets Factbook. Washington, International Finance Corporation.

Keppler, A.M., Traub, H.D., 1993. The small country effect: small markets be large markets, J. Invest. Fall, 17-24.

Liu, Y.A., Pan, M.S., Shieh, J.C.P., 1998. International Transmission of stock price movements: evidence form the US and Five Asian-Pacific markets. J. Econ. Finance 22, 59-69.

Masih, A.M., Masih, R., 1997. Dynamic Linkages and the Propagation Mechanism Driving Major International Stock Markets: An Analysis of the Pre-and Post-Crash Eras. Q. Rev. Econ. Finance 37, 859-885.

Masih, A.M., Masih, R., 1999. Are Asian stock market fluctuations due mainly to intra-regional contagion effects? Evidence based on Asian emerging stock markets. Pacific-Basin Finance J. 7, 251-282.

McNees, S.K., 1992. How large are economic forecast errors? N. Engl. Econ. Rev. July/Aug, 25-42. Meric, I.,

Meric, G., 1989. Potential gains from international portfolio diversification and inter-temporal stability and seasonality in international stock market relationships. J. Bank. Finance 13, 627-650. 
Newey, W., West, K., 1987. A simple positive semi-definite, heteroskedasticity and autocorrelation consistent covariance matrix. Econometrica 55, 703-708.

Palac-McMiken, E.D., 1997. An Examination of ASEAN Stock Markets: a Cointegration Approach. ASEAN Econ. Bull. 13, 299-311.

Pindyck, R.S., Rubinfeld, D.L., 1991. Economic Models and Economic Forecasts. McGraw-Hill, Singapore 504.

Rouwenhorst, K.G., 1999. European Equity Markets and the EMU. Financ. Anal. J. May/June, 57-64.

Roll, R., 1992. Industrial structure and the comparative behavior of international stock market indices. Journal of Finance 47, 3-41.

Serra, A.P., 2000. Country and industry factors in returns: evidence from emerging markets stocks. Emerg. Mark. Rev. 1, 127-151.

Sheng, H.C., Tu, A.H., 2000. A study of cointegration and variance decomposition among national equity indices before and during the period of the Asian financial crisis. J. Multinatl Financ. Manage. 10, 345-365.

Smith, K.L., Brocato, J., Rogers, J.E., 1993. Regularities in the data between major equity markets: evidence from Granger causality tests. Appl. Financ. Econ. 3, 55-60.

Standard and Poors, 2000. Emerging Stock Markets Factbook (Standard and Poors), p. 2.

White, H., 1980. A Heteroscedasticity Consistent Covariance Matrix Estimator and a Direct Test for Heteroscedasticity. Econometrics 48, 817-838.

Wolf, H.C., 1998. Determinants of emerging market correlations. In: Levich, R. (Ed.), Emerging Market Capital Flows. Kluwer Academic Publishers, Great Britain, pp. 219-235. 